\title{
Is arbutin an effective antioxidant for the discount of oxidative and nitrosative stress in Hep-G2 cells exposed to tert-butyl hydroperoxide?
}

\author{
Seyfizadeh $\mathrm{N}^{1}$, Tazehkand $\mathrm{MQ}^{1}$, Palideh $\mathrm{A}^{2}$, Maroufi $\mathrm{NF}^{3,4}$, Hassanzadeh $\mathrm{D}^{1}$, \\ Rahmati-Yamchi $\mathrm{M}^{5}$, Elahimanesh $\mathrm{F}^{6}$, Borzoueisileh $\mathrm{S}^{7}$ \\ Department of Radiology, Faculty of Paramedical Science, Kurdistan University of Medical Sciences, \\ Sanandaj, Iran. faridehelahimanesh@gmail.com
}

\begin{abstract}
AIM: Oxidative and nitrosative stress triggers an extensive damage to the tissues. Many herbal and chemical medicines have claimed to possess antioxidant properties. Arbutin exists in some plants such as Pyrus Biossierana Bushe. In this study, an inhibitory effect of arbutin against tert-butyl hydroperoxide induced cytotoxicity was studied using SYTOX TM Green assay for cell viability. The antioxidant effects of arbutin on the generation of malondialdehyde, nitric oxide, activity of oxidative enzyme (Superoxide dismutase and catalyze) and the amount of total thiol in Hep-G2 cells exposed to tert-butyl hydroperoxide were evaluated.

METHODS: Hep-G2 cells were cultured in 24-well plates. After 24 hours, the cells were pretreated with the arbutin at different concentrations $(0,100$ and $150 \mu \mathrm{M})$. 24 hours later, tert-butyl hydroperoxide at different concentrations $(0,150,200$ and $250 \mu \mathrm{M})$ was added into the culture media.

RESULTS: Arbutin was able to decrease malondialdehyde and nitric oxide concentrations in arbutin treated group in comparison with the control group $(p<0.00001)$. The catalase and superoxide dismutase enzymes in these cells were significantly decreased in a dose depend manner in the presence of arbutin in comparison with the control group $(p<0.00001)$. In addition, arbutin was capable of increasing the tert-butyl hydroperoxide mediated reduction in the total thiol amount in comparison with the control group $(p<0.00001$.)

CONCLUSION: Our investigation demonstrated that tert-butyl hydroperoxide evoked a reactive oxygen and nitrogen species overproduction in Hep-G2 cells. The cells treated with arbutin showed a dose-dependent reduction of tert-butyl hydroperoxide induced reactive oxygen and nitrogen species generation (Fig. 6, Ref. 34). Text in PDF www.elis.sk.

KEY WORDS: arbutin, nitrosative stress, oxidative stress, tert-butyl hydroperoxide, Hep-G2 cell line.
\end{abstract}

\section{Introduction}

Aerobic organisms are frequently exposed to oxidants. Reactive oxygen species (ROS) and reactive nitrogen species (RNS) are two major classes of oxidants. They play a critical role in the biological processes, but overproduction of these radicals may lead to a damage of tissues and organs, and that is associated with different diseases. Many oxidants are neutralized by the antioxi-

${ }^{1}$ Stem Cell Research Center, Tabriz University of Medical Sciences, Tabriz, Iran, ${ }^{2}$ Faculty of Dentistry, Babol University of Medical Sciences, Babol, Iran, ${ }^{3}$ Department of Clinical Biochemistry and Laboratory Medicine, Tabriz University of Medical Sciences, Tabriz, Iran, ${ }^{4}$ Student Research Committee, Tabriz University of Medical Sciences, Tabriz, Iran, ${ }^{5}$ Department of Clinical Biochemistry and Laboratory Medicine, Tabriz University of Medical Sciences, Tabriz, Iran, ${ }^{6}$ Department of Radiology, School of Paramedical Science, Kurdistan University of Medical Sciences, Sanandaj, Iran, and ${ }^{7}$ Cellular and Molecular Research Center, Yasuj University of Medical Sciences, Yasuj, Iran

Address for correspondence: F. Elahimanesh, Department of radiology, Faculty of Paramedical science, Kurdistan University of Medical Sciences, Sanandaj, Iran.

Phone: +989188782860 dant systems in the healthy biosystems, but an imbalance between them results in oxidative or nitrosative stress (1-3). Having high rates of free radical production or reduction of antioxidant defense system yields to the oxidation and thus might cause some serious damages to different biomolecules such as nucleic acids, proteins, carbohydrates and lipids (4-6). Coronary heart disease, cancer, neurodegenerative disorders, liver damage, aging, diabetes and metabolic syndrome seem to be associated with the increase in the levels of ROS and RNS (7-10). All tissues and organs are vulnerable to oxidative and nitrosative stress, but the liver, which is involved in detoxification, is more susceptible to these variations. Subsequently, most of the toxic substances aim to influence liver $(6,9)$. Hep-G2 cell line, derived from human hepatoma cells, is one of the most proper models to investigate in vitro xenobiotic metabolism, protective functions of antioxidants against oxidants and neutralizing the oxidative condition (9).

In order to neutralize damaging effects of oxidants, the organisms' antioxidant system and external antioxidants play a crucial role, arbutin is an effective external antioxidant, which can be extracted from many plants and fruits such as wheat, broccoli and pear. It also exists in the leaves of various plant species 


\section{9-575}

including bearberry (Arctostaphylos uva-ursi) and Telka (Pyrus Biossierana Bushe). Bearberry is with $20 \%$ arbutin, and uva ursi leaf standard with $10 \%$ arbutin $(11,12)$. It has been shown that arbutin is effective in the repulsion of kidney stones and possess antibacterial properties; it can be used as a cure for the urinary tract infections (13). In addition, some studies have reported that the arbutin does not have cytotoxic effects on the Hep-G2 cell line (11). However, arbutin suffers from q low bioavailability du eto its poor cell membrane penetration. Recently, many studies indicated that acylation modification of arbutin could increase its bioavailability(14). Tert-Butyl Hydroperoxide ( $t$-BHP) is an organic hydroperoxide with serious toxicity property. It could be metabolized to free radical intermediates. The subsequent result is the oxidative stress in the cells and tissues, which is not desired $(6,7,15)$. The major indicator of the oxidative stress is lipid peroxidation and free radicals, which, generated by the metabolization of $t$-BHP, may trigger the lipid peroxidation. The critical step in the degradation of the cell membranes is the raid of ROS and RNS on the double bonds of polyunsaturated fatty acids (PUFAs) to generate lipid hydroperoxides. The breakdown of hydroperoxides produces a great variety of aldehydes such as malondialdehyde (MDA), found to be increased in the various diseases. The extent of lipid peroxidation is estimated through the levels of $\operatorname{MDA}(8,16,17)$.

Another marker of nitrosative and oxidative stress is nitric oxide (NO). This important physiological messenger has crucial functions in mammalian cells. This signaling molecule is biologically produced from arginine, $\mathrm{O}_{2}$, and NADPH by nitric oxide syntheses in the cytochrome P450. Different physiological functions of nitric oxide are obtained by employing various types of NOS enzyme (neuronal, endothelial, inducible and mitochondria NOS). The excessive and unbalanced generation of NO also damage proteins, DNA and causes a cellular injury or death and thus results in nitrosative stress. An excessive nitric oxide is also associated with some well-known human diseases such as cardiovascular diseases (18). Nitrite is stable, nonvolatile and is determined as an index of NO level in nitrosative stress conditions.

Variety of antioxidants in human body provides a balance to the effect of oxidants. These substances can be categorized into two groups: enzymatic and non-enzymatic. The most important enzymatic antioxidants of human body are Superoxide dismutase (SOD) and catalase $(19,20)$. In addition to the antioxidant enzymes, there are also non-enzymatic antioxidants. Total thiol particularly thiol (-SH) groups excite on protein are measured as the main plasma antioxidants in vivo (19). In this study, we aim to evaluate the antioxidant properties of arbutin with a measurement of production of MDA and NO, changes in the activity of enzymatic and non-enzymatic antioxidants (SOD, Catalyse, Total thiol) in Hep-G2 cells exposed to $t$-BHP.

\section{Materials and methods}

The effects of arbutin on the oxidative and nitrosative stress in Hep-G2 cells exposed to tert-butyl hydroperoxide were examined.

\section{Cell line pretreatment and exposure}

The Hep-G2 cell line (National Cell Bank of Iran) at passage 4 cultured in RPMI-1640 (PAA, Austria) complemented with 10 $\%$ fetal bovine serum (FBS) and $1 \%$ penicillin-streptomycin (100 $\mathrm{IU} / \mathrm{ml}$ penicillin, $100 \mu \mathrm{g} / \mathrm{ml}$ streptomycin) was procured from Gibco, Germany. Arbutin and $t$-BHP were provided by the Sigma Chemical, St. Louis, USA. All other chemicals were of analytical grade. Hep-G2 cells were cultured in 24 -well plates $\left(2.5 \times 10^{5}\right.$ cells/well) and incubated at the standard culture conditions (at 37 ${ }^{\circ} \mathrm{C}+5 \% \mathrm{CO}_{2}$ in a humidified incubator. After 24 hour incubation, when the cells obtained a standard confluency, the supernatant medium was replaced with different concentrations of arbutin in a complete medium $(0,100$ and $150 \mu \mathrm{M})$. Afterward, several concentrations of $t$-BHP $(0,150,200$, and $250 \mu \mathrm{M})$ were added into the wells in the complete medium $(t=48 \mathrm{hrs})$. Control wells had only medium without arbutin and $t$-BHP. Finally, after 24 hour exposure to $t$-BPH ( $\mathrm{t}=72$ hours), the supernatant mediium was collected for investigating the oxidative stress by measuring $\mathrm{NO}$ and MDA levels (6).

\section{SYTOX TM Green Assay for Cell Viability}

SYTOX TM Green dye was used to assess the dead cells. Briefly, we had spun cells from an exponentially growing culture; $2000 \mathrm{rpm}$ for $5 \mathrm{mins}$ and pour off supernatant. After we took 0.3 $\mathrm{ml}$ cells, and added to $4.5 \mathrm{ml} 10 \mathrm{mM}$ EDTA pH 8.0 in a $5 \mathrm{ml} \mathrm{Fal-}$ con tube, we mixed and spun them 2000-rpm for5 mins. In next step, we discarded supernatant and resuspended pellet in $0.5 \mathrm{ml} 10$ mM EDTA pH 8.0 containing $0.1 \mathrm{mg} / \mathrm{ml}$ RNase A and left in $5 \mathrm{ml}$ Falcon tube and put in $37^{\circ} \mathrm{C}$ room for $2 \mathrm{~h}$. Then we added $0.5 \mathrm{ml}$ $10 \mathrm{mM}$ EDTA pH 8.0 containing $2 \mu \mathrm{M}$ ( $5 \mathrm{mM}$ stock) Sytox Green.

\section{Measurement of MDA concentration (TBARS assay)}

Concentration of MDA as a marker of lipid peroxidation was determined via thiobarbituric acid reactive substances (TBARS) assay in the supernatant medium of Hep-G2 cells. It is a reliable colorimetric test for determining the lipid peroxidation levels. This method is based on the reaction of two molecules of thiobarbituric acid (TBA) with one molecule of MDA. The final soluble contains the substances, which are responsible for the pink color (21). Absorption of the samples was red at $532 \mathrm{~nm}$ using a UVVis spectrophotometer (Jenway 6505, UK). The MDA concentration of samples was calculated using the extinction coefficient of $1.56 \times 10^{5} \mathrm{M}^{-1} \mathrm{~cm}^{-1}$.

\section{Measurement of Nitrite concentration (Griess Reaction Assay)}

Nitrites levels were assessed as the index of nitric oxide (NO) production by the Griess reaction after alteration of nitrate to nitrite by vanadium chloride $\left(\mathrm{VCL}_{3}\right)$. The Griess reaction test is based on the chemical reaction, which uses the sulfanilamide (SA), and $\mathrm{N}$-1-napthylethylenediamine dihydrochloride (NED) under acidic (phosphoric acid) conditions. In this study, the reduction of nitrate to nitrite was done by treating the samples with vanadium chloride. Nitrites levels were measured in the Hep- $\mathrm{G}_{2}$ cell medium by using the Griess reaction (22). The intense purple color of the product allowed the nitrite assay with a high sensitivity. The absorbance 

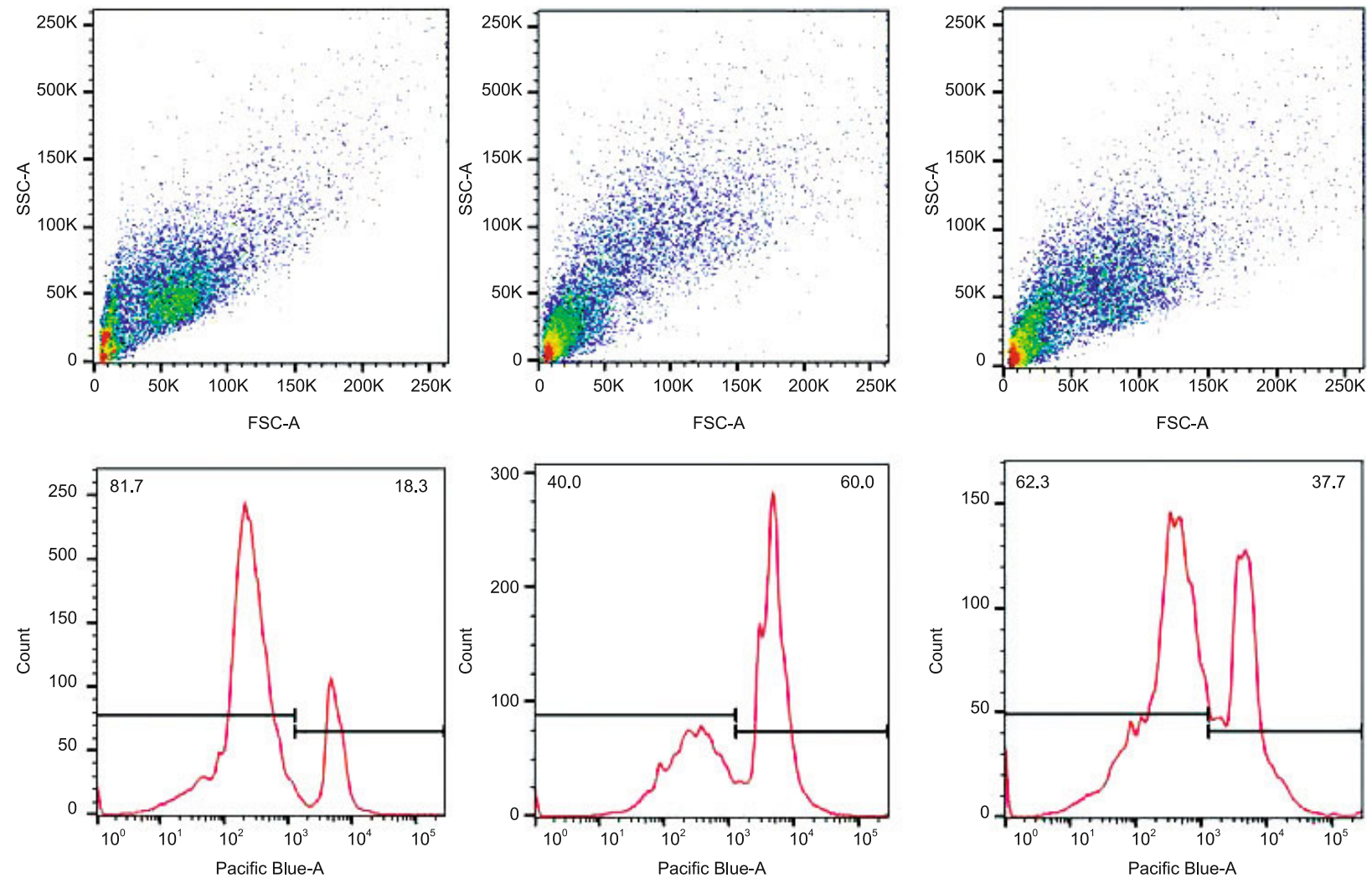

Control

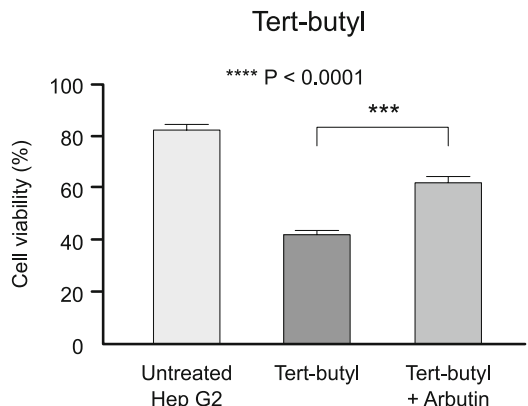

Tert-butyl + Arbutin

Fig. 1. Inhibitory effect of arbutin against t-BHP-induced cytotoxicity. Hep- $\mathrm{G}_{2}$ cells were incubated with arbutin (150 $\mu \mathrm{M}$ concentrations) for 24 hours and then incubated with t-BHP $(200 \mu \mathrm{M}$ concentrations) for another 24 hours and after that SYTOX TM Green assay for cell viability was done. Values are the mean \pm SEM. All experiments were done in triplicate.

of these samples at $540 \mathrm{~nm}$ is directly proportional to the nitrite levels in media (18).

\section{Measurement of antioxidant enzymes}

Superoxide dismutase (SOD) assay

SOD activity was evaluated in the cell lysate by the method based on the capability of the enzyme to inhibit the autoxidation of pyrogallol. In brief, $1 \mathrm{ml}$ of $45 \mathrm{mM}$ Tris-Hcl buffer containing EDTA was added to $25 \mu \mathrm{l}$ of cell lysate supernatan and then $50 \mu \mathrm{l}$ of pyrogallol $0.2 \mathrm{mM}$ was mixed with above solution and the absorbance of samples was calculated at $420 \mathrm{~nm}$ every 15 seconds quickly, the measurement was continued for two minutes. The activity of SOD is proportional to the inhibition of the pyrogal- lol oxidation in the sample. SOD enzyme unit is considered as an enzyme inhibitory capability (23).

\section{Catalase activity (CAT) assay}

The activity of catalase was measured by its capacity to decompose $\mathrm{H}_{2} \mathrm{O}_{2}$. For this aim, one unit of catalase was required for one $\mu \mathrm{M}$ in 1 minute. We added $1.0 \mathrm{~mL}$ of $20 \mathrm{mM}$ freshly prepared $\mathrm{H}_{2} \mathrm{O}_{2}$. Breakdown level of $\mathrm{H}_{2} \mathrm{O}_{2}$ was measured by spectrophotometer at $240 \mathrm{~nm}$ for 2 minutes. U/mg of protein was the unit for enzyme activity (24).

\section{Measurement of total thiol}

One of the markers of free radical damage is serum thiol groups. This sensitive marker is reduced in oxidative damage. The 


\section{9-575}

appropriate assay for detecting the total thiol is HU colorimetric assay. According to this method, yellow complex of 2, 2 Dithiodibenzoic acid (DTNB indicator) with thiol groups is measured by spectrophotometry at 412 wave length (25).

\section{Statistical analysis}

The normality of data was tested via Kolmogorov-Smirnov $(\mathrm{K}-\mathrm{S})$ test. Data were reported as the mean \pm SEM. One-way ANOVA with Tukey as a post-hoc test was used to compare the differences of measured concentrations in the studied groups and $\mathrm{p}<0.05$ was considered as statistically significant.

\section{Results}

In vitro dead cell staining with the high-affinity nucleic acid stain sytox showed that adding arbutin into the Hep-G2 cells' media $(150 \mu \mathrm{M}$ for $24 \mathrm{hr})$ reduced cell death due to $t$-BPH $(\mathrm{p}<$ 0.00001 ) (Fig. 1). Adding arbutin into the Hep-G2 cells' media fully improved the total antioxidative capacity and decreased the $t$-BPH oxidative effects. The cytotoxicity of $t$-BPH was significantly reduced by the arbutin pretreatment at some concentrations $(100$ and $150 \mu \mathrm{M})(\mathrm{p}<0.01)$. The production of MDA and nitrites in the media were linearly associated to the t-BPH cytotoxicity and arbutin was able to decrease the lipid peroxidation level and nitrite concentrations in the Hep-G2 cells media (Figs 2 and 3 , respectively) $(\mathrm{p}<0.00001)$.

Our study showed that pretreatment of Hep-G2 cells with 100 and $150 \mu \mathrm{M}$ of arbutin for 24 hours protected cells from the oxidative stress induced by $t$-BHP. We report a significant increase in the MDA and nitrite levels of the Hep-G2 cells without including any arbutin in the cell culture medium. Unavoidable cell damage is a direct result of increased level of MDA and nitrite. In fact,

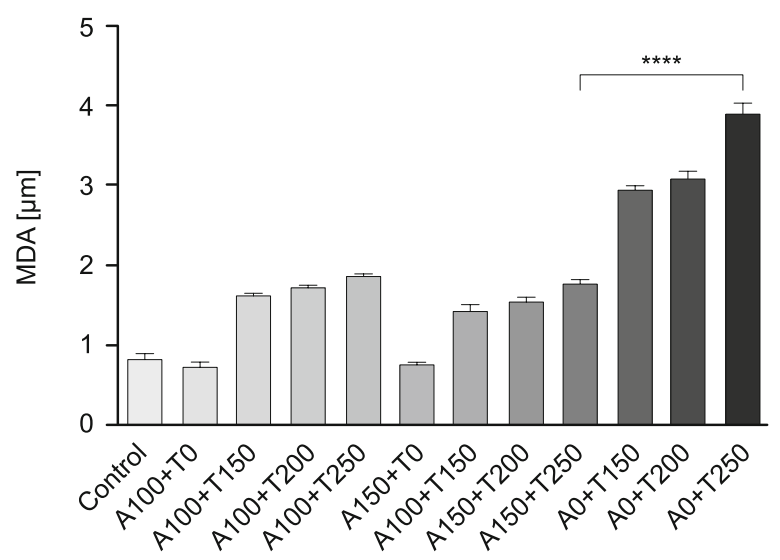

Fig. 2. Inhibitory effect of arbutin on MDA concentration against tBHP-induced toxicity. Hep- $\mathrm{G}_{2}$ cells were incubated with arbutin $(0$, 100 and $150 \mu \mathrm{M}$ concentrations) for 24 hours and then incubated with t-BHP $(0,150,200$ and $250 \mu \mathrm{M}$ concentrations $)$ for another 24 hours. Nitrosative stress marker (Nitric Oxide metabolite) was measured by Griess reaction. Values are the mean \pm SEM. $(A=$ arbutin, $T=t-B H P$ and $\mathrm{CTL}=$ control group), $* * * * \mathbf{p}<\mathbf{0 . 0 0 0 0 1}$. All experiments were done in triplicate.

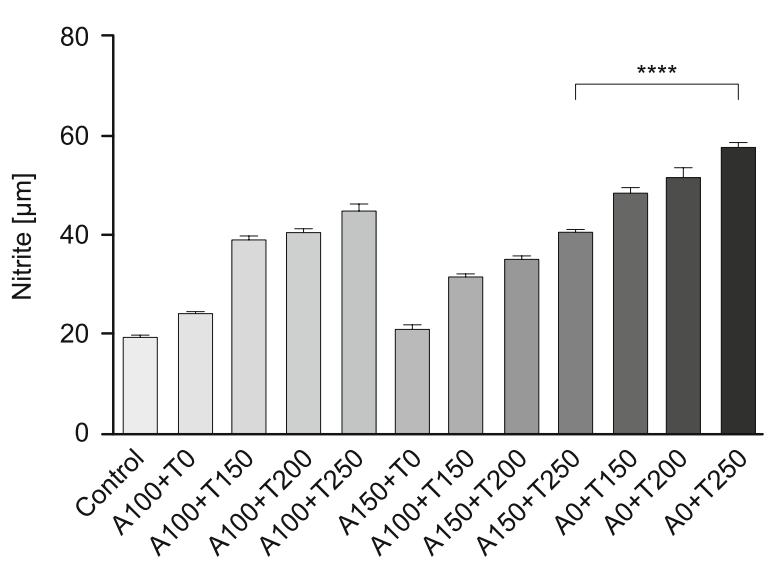

Fig. 3. Inhibitory effect of arbutin on nitrite concentration against tBHP-induced toxicity. Hep- $G_{2}$ cells were incubated with arbutin $(0$, 100 and $150 \mu \mathrm{M}$ concentrations) for 24 hours and then incubated with t-BHP $(0,150,200$ and $250 \mu \mathrm{M}$ concentrations) for another 24 hours. Lipid peroxidation marker (MDA) was measured by TBARS assay. Values are the mean \pm SEM. $(A=$ arbutin, $T=t-B H P$ and $C T L=$ control group). ${ }^{* * *} \mathbf{p}<\mathbf{0 . 0 0 0 0 1}$. All experiments were done in triplicate.

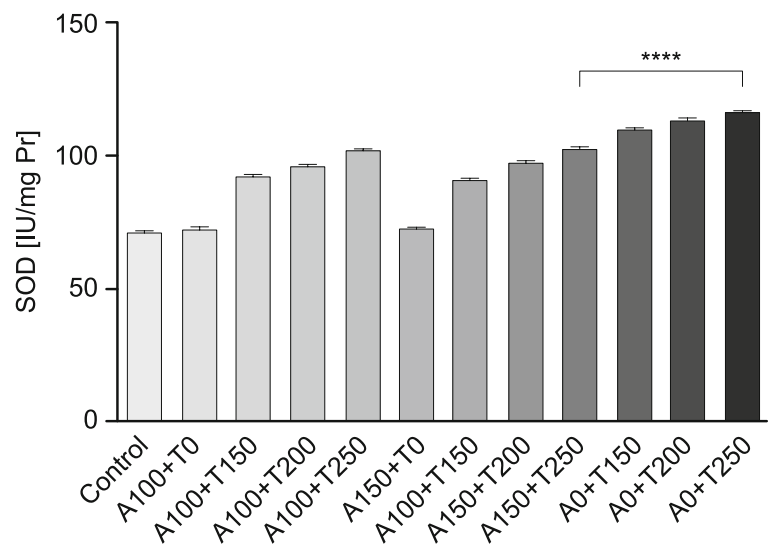

Fig. 4. The effect of arbutin on t-BHP treated cells on antioxidant enzyme (SOD) activity. $\mathrm{Hep}_{-} \mathrm{G}_{2}$ cells were incubated with arbutin $(0$, 100 and $150 \mu \mathrm{M}$ concentrations) for 24 hours and then incubated with t-BHP $(0,150,200$ and $250 \mu \mathrm{M}$ concentrations) for another 24 hours. Arbutin was capable to decrease the t-BHP mediated increase SOD enzymes significantly (SOD $=$ superoxide dismutase $A=\operatorname{arbutin}, T=$ t-BHP) $(* * * * \mathbf{p}<0.00001)$. All experiments were done in triplicate

doses of 200 and $250 \mu \mathrm{M}$ of $t$-BHP used in this study are strongly aggressive and lethal to the Hep-G2 cells $(\mathrm{p}<0.00001)$.

The effect of arbutin on t-BHP treated cells on antioxidant enzymes was evaluated and the results given in catalase and SOD activities were increased in comparison with the control group in HepG2 cells when exposed to t-BHP. Arbutin was capable to decrease the t-BHP mediated increase of catalase and SOD enzymes in these cells significantly in a dose dependent manner ( $\mathrm{p}$ $<0.00001$ ) (Figs 4 and 5).

To confirm the antioxidant properties more, the total thiol was measured. The results showed that treatment with t-BHP reduced the amount of total thiol compared to the control group. Arbutin 


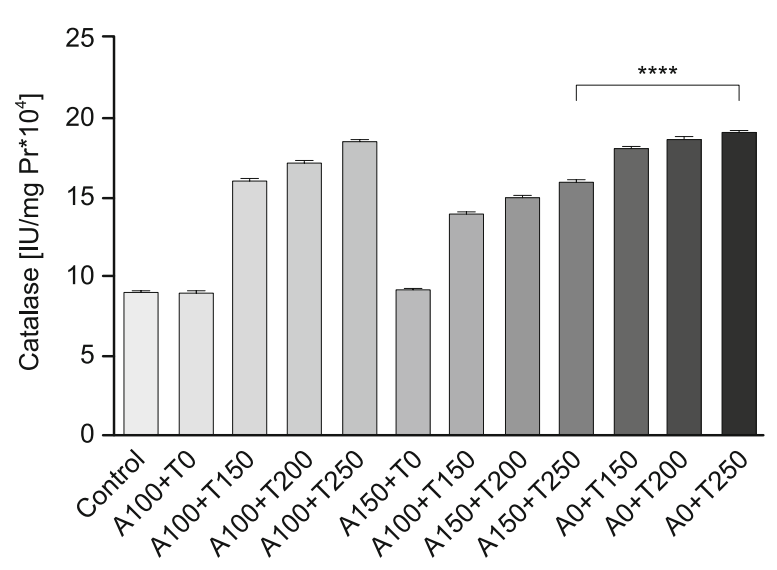

Fig. 5. The effect of arbutin on t-BHP treated cells on antioxidant enzyme (Catalyse) activity. Hep- $G_{2}$ cells were incubated with arbutin $(0,100$ and $150 \mu \mathrm{M}$ concentrations) for 24 hours and then incubated with t-BHP $(0,150,200$ and $250 \mu \mathrm{M}$ concentrations) for another 24 hrs. Arbutin was capable of decreasing the t-BHP mediated increase of Catalyse significantly $(A=$ arbutin, $T=t-B H P)$ $(* * * * \mathbf{p}<0.00001)$. All experiments were done in triplicate.

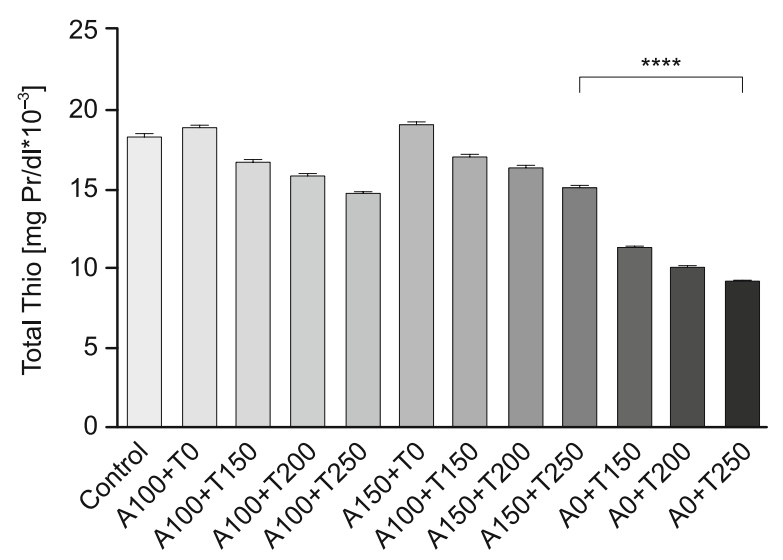

Fig. 6. Inhibitory effect of arbutin on t-BHP-induced thiol oxidation. Hep- $G_{2}$ cells were incubated with arbutin $(0,100$ and $150 \mu \mathrm{M}$ concentrations) for 24 hours and then incubated with t-BHP $(0,150,200$ and $250 \mu \mathrm{M}$ concentrations) for another $24 \mathrm{hrs}$. Values are the mean \pm SEM $(\mathrm{A}=$ arbutin, $\mathrm{T}=\mathrm{t}-\mathrm{BHP})(* * * * \mathbf{p}<\mathbf{0 . 0 0 0 0 1})$. All experiments were done in triplicate.

was capable to increase the t-BHP mediated reduction in the total thiol amount. This increase was statistically significant and occurred in a dose-dependent manner $(\mathrm{p}<0.00001)$ (Fig. 6).

\section{Discussion}

Oxidative and nitrosative stress damages cellular macromolecules and may cause the development of chronic diseases (26). As we mentioned, all organs are vulnerable to the oxidative and nitrosative stress, but liver is the main target of toxicants, which are constituted by hepatocytes, so it is more susceptible to the oxidative stress $(9,27)$. Consequently, we chose Hep-G2 cell line for this study. The choice of t-BHP is based on the previous research from our and other laboratories $(9,27,28)$. Tert- Butylhydroperoxide ( $t$-BHP) could be metabolized to free radical mediators, which create oxidative stress condition $(15,28)$. The $t$-BHP can be metabolized in the Hep-G2 cells by glutathione peroxidase enzyme, producing oxidized glutathione (GSSG) (29). Likewise, $t$-BHP can be broken down into peroxyl and alkoxyl free radicals by cytochrome $\mathrm{P} 450$ pathway and by free iron-dependent reactions. Therefore, the production of radicals might damage the two-layer lipid membranes and the polyunsaturated lipids. As the result, it produces the MDA and other biomarkers of nitrosative stress, such as NO* and nitrites.

The fundamental hypothesis of our study is consistent with the theory that arbutin is an antioxidant and can discount the oxidative stress conditions. Our previous study showed that arbutin had antioxidant properties and could increase ferric reducing antioxidant power (measured by FRAP test) and cell viability (measured by MTT assay and Trypan Blue test) in Hep-G2 cell line (27). Also Dadgar $M$ et al showed that arbutin attenuated the behavioral impairment and oxidative stress in the PD animal model (30). This study is in accordance with our previous investigation and Dadgar $\mathrm{M}$ et al study. The results demonstrated that arbutin had protective effects against the $t$-BHP-induced toxicity in Hep-G2 cells and that the presence of arbutin in the media could significantly decrease the level of biomarkers of nitrosative and oxidative stress (i.e. NO and MDA levels) (Figs 2 and 3). Our results also showed that arbutin could reduce the amount of antioxidant enzyme activity that had been increased with treatment of $t$-BHP (Figs 4 and 5). Also, arbutin has an inhibitory effect on t-BHP-induced thiol oxidation.

The production of the large amounts of $\mathrm{NO}^{-}$(as a cytotoxic agent) to destroy tumor cells or microbes has genotoxic and cytotoxic effects and this process may damage DNA and proteins. Nitric oxide and $\mathrm{O}_{2}^{-}$can also produce peroxynitrite (ONOO-) and they may damage the cellular constituent with the processes similar to the processes, in which the chemical oxidants act. From both reactions the end result would be an intensification of the oxidative and nitrosative stress conditions (31). We showed a significant reduction in nitrites levels in the Hep-G2 cells when we added arbutin in the medium. That is crucial for the cells to maintain the levels of $\mathrm{NO}^{*}$ and nitrites production lower than the threshold value, which could cause serious damage to the cells. On the other hand, the $\mathrm{NO}^{*}$ and nitrites production increases due to t-BHP metabolism. Therefore, pretreating by arbutin can control the NO* production and avoid the cellular damage caused by t-BHP (Fig. 3).

It was reported that arbutin has antioxidative effects on the bilayer lipids of cell membranes (32). Phenolic compounds that commonly exist in plants have been recognized to play a critical role as dietary antioxidants for the prevention of oxidative stress in biological systems (6). The cells that were exposed to arbutin (phenolic compound) demonstrated a dose-dependent reduction of $t$-BHP-induced ROS and RNS in the Hep-G2 medium.

A number of studies have demonstrated correlations between antioxidative property and the hepatoprotective effects of flavonoids and phenolic compounds. The antioxidant characteristic of 
flavonoids relates to their structure. So, probably the hepatoprotective effects of the flavonoids and phenolic compounds were made through free radical scavenging activity $(33,34)$. The effect of arbutin on hepatocellular carcinoma and nitric oxide levels in oxidative and nitrosative stress situation has not been extensively studied until now. In this study, analyzing MDA and nitrites levels clearly showed that the pretreatment of Hep-G2 cells with arbutin strongly protected the cells against oxidative and nitrosative stress. The presence of arbutin in the range of physiological doses may prepare the antioxidant defense system of the cell to be exposed the stressors. Perhaps the hydroxyl groups and double bonds in the arbutin structure may be involved as an obvious free radicals target site; thus, it may be an explanation of radical scavenging activity of arbutin.

In this study, we only discussed the enzymatic and non-enzymatic antioxidant and it was a limitation of our study. It is advisable to study the pathways involved in antioxidant properties of arbutin also at the molecular level in order to study the mechanisms properly. It is also better to use anti-oxidant arbutin at the level of animal models as well as clinical trials to confirm the findings of this study.

\section{Conclusion}

Our investigation demonstrated that $t$-BHP evoked a reactive oxygen and nitrogen species overproduction in the Hep-G2 cells. The data further displayed that the cells treated with arbutin showed a dose-dependent reduction of $t$-BHP-induced ROS and RNS generation. Thus, arbutin may be used as an effective antioxidant complement against liver damage, where oxidative and nitrosative stress has a critical role.

\section{References}

1. Pitocco D, Zaccardi F, Di Stasio E, Romitelli F, Santini SA, Zuppi C et al. Oxidative stress, nitric oxide, and diabetes. RDS 2010; 7 (1): 15.

2. Shiralizadeh J, Barmaki H, Haiaty S, Faridvand Y, Mostafazadeh M, Mokarizadeh N et al. The effects of high and low doses of folic acid on oxidation of protein levels during pregnancy: a randomized double-blind clinical trial. Horm Mol Biol Clin Investig 2017; 33 (3).

3. Nozari S, Maroufi NF, Nouri M, Oskouei MP, Shiralizade J, Yekani F et al. Decreasing serum homocysteine and hypocholesterolemic effects of Bovine lactoferrin in male rat fed with high-cholesterol diet. JCVTR 2018; 10 (4): 203.

4. Halliwell B, Gutteridge JM. [1] Role of free radicals and catalytic metal ions in human disease: an overview. Methods Enzymol. 186: Elsevier; 1990. p. 1-85.

5. Katoch B, Begum R. Biochemical basis of the high resistance to oxidative stress inDictyostelium discoideum. J Biosci 2003; 28 (5): 581-588.

6. Lima CF, Fernandes-Ferreira M, Pereira-Wilson C. Phenolic compounds protect $\mathrm{HepG} 2$ cells from oxidative damage: relevance of glutathione levels. Life Sci 2006; 79 (21): 2056-2068.

7. Sohn JH, Han K-L, Lee S-H, Hwang J-K. Protective effects of panduratin A against oxidative damage of tert-butylhydroperoxide in human HepG2 cells. Biol Pharm Bull 2005; 28 (6): 1083-1086.
8. Lima CF, Valentao PC, Andrade PB, Seabra RM, Fernandes-Ferreira M, Pereira-Wilson C. Water and methanolic extracts of Salvia officinalis protect $\mathrm{HepG} 2$ cells from t-BHP induced oxidative damage. Chem Biol Interact 2007; 167 (2): 107-115.

9. Vidyashankar S, Mitra S, Nandakumar KS. Liv. 52 protects HepG2 cells from oxidative damage induced by tert-butyl hydroperoxide. Mol Cell Biochem 2010; 333 (1-2): 41.

10. Mahjoub S, Ahmadi MH, Faramarzi M, Ghorbani H, Moazezi Z. The prevalence of metabolic syndrome according to the Iranian Committee of Obesity and ATP III criteria in Babol, North of Iran. Caspian J Intern Med 2012; 3 (2): 410.

11. Khanal T, Kim HG, Hwang YP, Kong MJ, Kang MJ, Yeo HK et al. Role of metabolism by the human intestinal microflora in arbutin-induced cytotoxicity in HepG2 cell cultures. Biochem Biophys Res Commun 2011; 413 (2): 318-324.

12. Shahaboddin M-E, Pouramir M, Moghadamnia A-A, Parsian H, Lakzaei M, Mir H. Pyrus biossieriana Buhse leaf extract: An antioxidant, antihyperglycaemic and antihyperlipidemic agent. Food Chem 2011; 126 (4): $1730-1733$

13. Funayama M, Arakawa H, Yamamoto R, Nishino T, Shin T, Murao $S$. Effects of $\alpha$-and $\beta$-arbutin on activity of tyrosinases from mushroom and mouse melanoma. Biosci Biotechnol Biochem 1995; 59 (1): $143-144$.

14. Li X, Xu H, Zhao G, Wu H, Yu Y, Lai F et al. Highly efficient synthesis of arbutin esters catalyzed by whole cells of Candida parapsilosis. RSC Advances 2018; 8 (18): 10081-10088.

15. Noh J-R, Gang G-T, Kim Y-H, Yang K-J, Hwang J-H, Lee H-S et al. Antioxidant effects of the chestnut (Castanea crenata) inner shell extract in t-BHP-treated HepG2 cells, and CCl4-and high-fat diet-treated mice. Food Chem Toxicol 2010; 48 (11): 3177-3183.

16. Wang B-J, Liu C-t, Tseng C-Y, Wu C-P, Yu Z-R. Hepatoprotective and antioxidant effects of Bupleurum kaoi Liu (Chao et Chuang) extract and its fractions fractionated using supercritical $\mathrm{CO} 2$ on $\mathrm{CCl} 4$-induced liver damage. Food Chem Toxicol 2004; 42 (4): 609-617.

17. Mahjoub S, Tamaddoni A, Nikoo MZ, Moghadamnia AA. The effects of beta-carotene and vitamin $\mathrm{E}$ on erythrocytes lipid peroxidation in beta-thalassemia patients. J Res Med Sci 2007; 12 (6): 301-307.

18. Sun J, Zhang X, Broderick M, Fein H. Measurement of nitric oxide production in biological systems by using Griess reaction assay. Sensors 2003; 3 (8): 276-284.

19. Kolagal V, Karanam S, Dharmavarapu P, D'Souza R, Upadhya $\mathbf{S}$, Kumar $\mathbf{V}$ et al. Determination of oxidative stress markers and their importance in early diagnosis of uremia-related complications. Indian J Nephrol 2009; 19 (1): 8.

20. Khadem-Ansari M-H, Asoudeh M, Gheshlaghi HFK, Nozari S, Zarringol M, Maroufi NF et al. Copper and zinc in stage I multiple myeloma: relation with ceruloplasmin, lipid peroxidation, and superoxide dismutase activity. Horm Mol Biol Clin Investig 2018.

21. Kim M-K, Lee H-S, Kim E-J, Won N-H, Chi Y-M, Kim B-C et al. Protective effect of aqueous extract of Perilla frutescens on tert-butyl hydroperoxide-induced oxidative hepatotoxicity in rats. Food Chem Toxicol 2007; 45 (9): 1738-1744.

22. Coneski PN, Schoenfisch MH. Nitric oxide release: part III. Measurement and reporting. Chem Soc Rev 2012; 41 (10): 3753-3758. 
23. Gao R, Yuan Z, Zhao Z, Gao X. Mechanism of pyrogallol autoxidation and determination of superoxide dismutase enzyme activity. BBioelectrochem Bioenerg 1998; 45 (1): 41-45.

24. Méndez-Álvarez E, Soto-Otero R, Sánchez-Sellero I, López-Rivadulla Lamas M, editors. In vitro inhibition of catalase activity by cigarette smoke: relevance for oxidative stress. Journal of Applied Toxicology: An International Forum Devoted to Research and Methods Emphasizing Direct Clinical, Industrial and Environmental Applications; 1998: Wiley Online Library.

25. Hu M, Dillard C. Plasma SH and GSH measurement. Methods Enzymol 1994; 233 (385): 87.

26. Alía M, Ramos S, Mateos R, Bravo L, Goya L. Response of the antioxidant defense system to tert-butyl hydroperoxide and hydrogen peroxide in a human hepatoma cell line (HepG2). J Biochem Mol Toxicol 2005; 19 (2): 119-128.

27. Seyfizadeh N, Mahjoub S, Zabihi E, Moghadamnia A, Pouramir M, Mir $\mathbf{H}$ et al. Cytoprotective effects of arbutin against tert-butyl hydroperoxid induced toxicity in Hep-G2 cell line. World Appl Sci J 2012; 19 (2): 163-167.

28. Alía M, Ramos S, Mateos R, Granado-Serrano AB, Bravo L, Goya L. Quercetin protects human hepatoma HepG2 against oxidative stress induced by tert-butyl hydroperoxide. Toxicol Appl Pharmacol 2006; 212 (2): 110-118.
29. Rush GF, Gorski JR, Ripple MG, Sowinski J, Bugelski P, Hewitt WR. Organic hydroperoxide-induced lipid peroxidation and cell death in isolated hepatocytes. Toxicol Appl Pharmacol 1985; 78 (3): 473-483.

30. Dadgar M, Pouramir M, Dastan Z, Ghasemi-Kasman M, Ashrafpour M, Moghadamnia AA et al. Arbutin attenuates behavioral impairment and oxidative stress in an animal model of Parkinson's disease. J Phytomed 2018; 8 (6): 533.

31. Xu L, Xie K, Fidler IJ. Therapy of human ovarian cancer by transfection with the murine interferon $\beta$ gene: role of macrophage-inducible nitric oxide synthase. Hum Gene Ther 1998; 9 (18): 2699-708.

32. Hincha DK, Oliver AE, Crowe JH. Lipid composition determines the effects of arbutin on the stability of membranes. Biophys J 1999; 77 (4): 2024-2034.

33. Kim SM, Kang K, Jho EH, Jung YJ, Nho CW, Um BH et al. Hepatoprotective effect of flavonoid glycosides from Lespedeza cuneata against oxidative stress induced by tert-butyl hyperoxide. Phytother Res 2011; 25 (7): 1011-1017.

34. Khadir F, Pouramir M, Joorsaraee SG, Feizi F, Sorkhi H, Yousefi F. The effect of arbutin on lipid peroxidation and antioxidant capacity in the serum of cyclosporine-treated rats. Caspian J Intern Med 2015; 6 (4): 196.

Received April 16, 2019. Accepted May 30, 2019. 